\title{
Uso da internet em sala de aula*
}

\section{Internet using in classrooms}

\author{
José Armando Valente**
}

\begin{abstract}
RESUMO
A internet, mais especificamente a World Wide Web (Web), constitui hoje um dos meios mais sofisticados de uso da informática na educação. Este trabalho discute o que é internet e as diversas maneiras como ela tem sido usada educacionalmente, inclusive no suporte à educação a distância. Ela pode ser usada tanto para fornecer informação, complementando a visão instrucionista do processo ensino-aprendizagem; quanto ser usada na elaboração de atividades que auxiliem o aprendiz na construção de seu conhecimento. As discussões apresentadas indicam que o uso na modalidade instrucionista ou na construção de conhecimento é determinada pela intenção pedagógica do professor.

Palavras-chave: internet, ensino-aprendizagem, construção de páginas Web, construção de conhecimento.
\end{abstract}

\begin{abstract}
Internet, more specifically the Word Wide Web (Web), constitutes today one of the most sophisticated means of using computers in education. This work discusses what is Internet and several ways it can be used educationally, including its support of distance education. It can be used as a source of information, complementing the instructionist view of teaching process; or used to develop activities that contribute to the learner's construction of knowledge. The discussion indicates that the use of Internet according to the
\end{abstract}

* Este artigo foi baseado na palestra apresentada na programação de Formação Continuada de Educadores do Itaú Cultural.

** Professor do Departamento de Multimeios e Núcleo de Informática Aplicada à Educação, da Universidade Estadual de Campinas. jvalente@unicamp.br 
instructionist approach, or in the construction of knowledge, is determined by the teacher's pedagogical intentions.

Key-words: Internet, ensino-aprendizagem, construção de páginas Web, construção de conhecimento.

\section{Introdução}

A internet é hoje um dos mais poderosos meios de comunicação. É global, cresce rapidamente e atinge praticamente todos os cantos do planeta. Estimamos que existam atualmente 377 milhões de pessoas usando a internet (Report of the Web-Based Education Commission, 2000).

$\mathrm{Na}$ educação, o uso da internet representa atualmente o maior potencial de aplicação das Tecnologias da Informação e da Comunicação (TIC). A internet pode ser vista como grande repositório de informação, onde é possível encontrar assuntos sobre praticamente todas as áreas do conhecimento. Além disso, a internet dispõe dos mais modernos recursos para a manipulação da informação. Essas características contribuem para que tanto alunos quanto professores concordem que a internet seja um dos meios mais explorados educacionalmente (BENTON, 2001).

No entanto, enfatizo o aspecto "potencial", pois a Internet pode ser utilizada no processo de construção de conhecimento e, nesse sentido, revolucionar as abordagens educacionais tradicionais; ou ser utilizada para complementar ou subsidiar os processos de transmissão de informação que ainda persistem na grande maioria das escolas.

O livro de HEIDE; STILBORNE (2000) é um interessante guia sobre como usar a internet na educação. Essas autoras mostram que a internet pode ser usada para auxiliar o aluno a pesquisar sobre um determinado assunto e a desenvolver projetos, na comunicação com outras pessoas, para publicar os resultados de trabalhos, e no desenvolvimento profissional por intermédio da Educação a Distância. Portanto, todas estas diferentes utilizações podem estar contribuindo para o aprendiz construir novos conhecimentos ou ser em usada, para transmitir informação, incrementando a visão bancária da educação, como mencionado por PAULO FREIRE (1970).

Neste artigo serão discutidos, inicialmente, o que é a internet, as abordagens pedagógicas do instrucionismo e do construcionismo e em seguida, como a internet pode ser utilizada na abordagem instrucionista e no 
construcionismo e finalmente, uma breve visão de como a internet pode ser usada na Educação a Distância. O objetivo é mostrar que a presença da internet, ou do computador em si, não é garantia para que o aluno construa conhecimento. Cabe ao professor saber explorar os potenciais educacionais oferecidos pela internet ou pelo computador e criar situações para o aluno poder significar e compreender a informação obtida e com isso, construir novos conhecimentos.

\section{O que é a internet}

A internet é uma extensa rede de redes de computadores. A rede mais básica pode ser constituída ao redor de um provedor. Esse provedor, geralmente, é uma instituição que permite que computadores pessoais $(\mathrm{p} 1, \mathrm{p} 2, \ldots)$ - ou de outras instituições (inst1, inst $2, \ldots$ ) com suas redes locais de computadores $(\mathrm{c} 1, \mathrm{c} 2, \ldots)$ - conectem- se aos seus computadores, formando uma rede. Os provedores existentes ao redor do planeta (prov1, prov2,...), por sua vez, estão interligados, constituindo uma outra rede, denominada de internet - interligação de redes, como mostrado na figura 1.

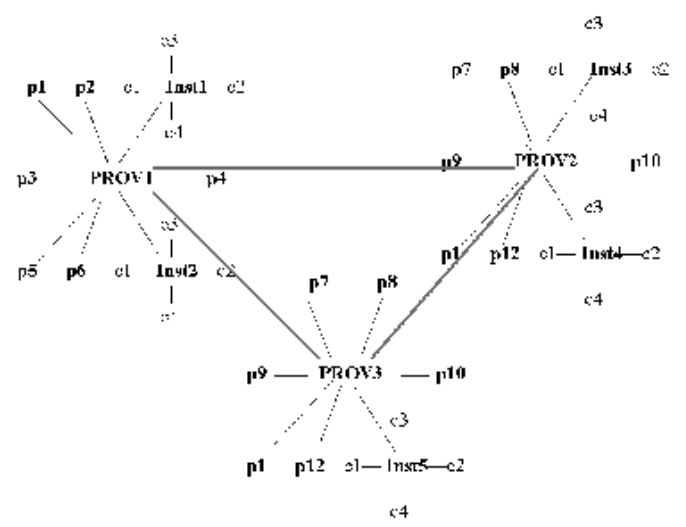

Figura 1 - INTERLIGAÇÃO DE REDES DE REDES DE COMPUTADORES, CONSTITUINDO A INTERNET.

A internet oferece diversas ferramentas de acesso à informação como correio eletrônico (e-mail), grupo de discussão (chat groups), recursos 
para transferência de arquivos (FTP ou file transfer protocol) que, atualmente, são integrados no Word Wide Web (WWW). A WWW é hoje a mais conhecida e disseminada ferramenta a ponto de as pessoas confundirem a Web com a internet.

O meio para tornar disponível uma informação na Web é via páginas Web. Cada indivíduo ou instituição pode criar suas páginas Web, armazenando-as no seu próprio computador ou nos computadores do provedor. Isso tem a vantagem de disseminar e possibilitar uma verdadeira democratização às mais variadas informações. Por outro lado, o que é disponibilizado pode ou não ter sido validado de acordo com parâmetros científicos ou éticos. Cabe ao usuário saber discernir e avaliar a informação obtida.

Assim a internet e principalmente a Web, cria verdadeiros desafios de ordem pedagógica ao mesmo tempo em que pode ser importante recurso educacional, auxiliando o desenvolvimento de capacidades e habilidades fundamentais para a sobrevivência em um mundo permeado de informação. No entanto, o desenvolvimento dessas habilidades depende da ênfase do processo de ensino-aprendizagem e da intenção pedagógica do professor. $\mathrm{Na}$ internet é possível encontrar tutoriais prontos para ensinar qualquer assunto ou a informação "pronta" sobre qualquer tópico. É muito fácil o aprendiz selecionar e colar (cópia eletrônica) essa informação, sem mesmo ter entendido o que copiou. A ênfase aqui é o instrucionismo - a instrução, o fazer ou a memorização da informação. Por outro lado, é possível criar situações nas quais o aprendiz tem que aplicar a informação obtida, por exemplo, na resolução de projetos ou problemas. Isso exige a significação ou interpretação da informação de acordo com conhecimentos prévios do aprendiz e, com isto, construindo novos conhecimentos. A ênfase aqui é o compreender na visão de PIAGET (1978) ou o construcionismo na visão de PAPERT (1986).

Assim, do ponto de vista educacional, a internet pode contribuir tanto para a instrução quanto para a construção de conhecimento. A ênfase está no aspecto pedagógico do seu uso e não na internet em si. Porém, antes de mostrar os diferentes usos pedagógicos da internet, é importante entender como o computador pode ser usado na educação segundo as abordagens instrucionista e construcionista. 


\section{As abordagens instrucionista e construcionista}

A abordagem instrucionista é tipicamente implementada por software educacional do tipo tutorial, exercício-e-prática ou alguns jogos. Nesses casos, a informação é organizada de acordo com uma seqüência pedagógica. $\mathrm{O}$ aluno pode seguir esta sequiência ou pode escolher a informação que desejar. No caso de seguir a seqüência, o software tem o controle do processo de ensino e o aprendiz pode mudar de tópico, simplesmente apertando a tecla ENTER ou o software altera a seqüência de acordo com as respostas fornecidas pelo aluno. No caso de poder escolher, o aprendiz tem o controle e pode selecionar o que deseja. Em geral, softwares que permitem a escolha de informações são organizados na forma de hipertextos (textos interligados) e passar de um hipertexto para outro constitui a ação de "navegar" no software.

Tanto no caso do controle estar no software, quanto no caso do aluno poder escolher a seqüência a ser seguida, existe uma organização previamente definida da informação. A interação entre o aprendiz e o computador consiste na leitura da tela (ou escuta da informação fornecida), no avanço, na sequiência de informação, na escolha de informação, e na resposta de perguntas que são fornecidas ao sistema. $\mathrm{O}$ esquema na figura 2 ilustra essa situação de uso de um software educacional do tipo tutorial.

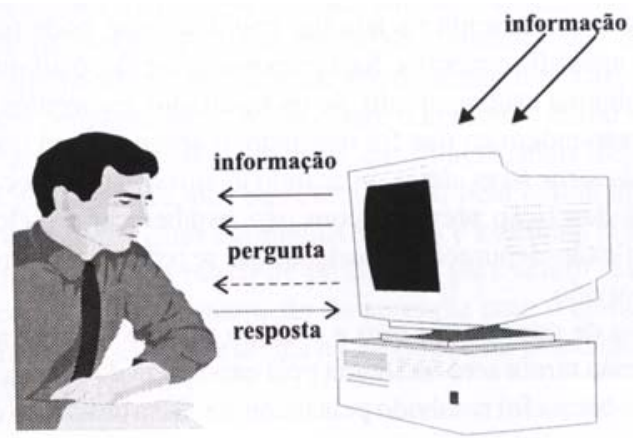

Figura 2 - ALUNO INTERAGINDO COM O COMPUTADOR POR INTERMÉDIO DE UM SOFTWARE EDUCACIONAL

O comportamento de um aluno usando um software educacional não é, necessariamente, de passividade. $\mathrm{O}$ aprendiz pode estar ativo, fazendo coisas. Entretanto, não temos qualquer pista se está processamento a informação 
recebida e se está entendendo o que está fazendo. O interessante é que ele pode até estar processando a informação, porém o tipo de interação com o computador não oferece meios para verificar quando e como isso está acontecendo. Muito pelo contrário. Se o aprendiz for muito criativo, ele pode fornecer uma resposta que não se enquadra no repertório de respostas previamente preparadas e o sistema certamente irá considerá-la como sendo errada.

Para se certificar de que a informação está sendo processada, é necessário apresentar ao aprendiz situações-problema, onde ele é obrigado a usar as informações fornecidas. Alguns softwares educacionais tentam fazer isso mas, em geral, o problema apresentado se resume em verificar se o aprendiz memorizou a informação fornecida ou requer uma aplicação direta da informação fornecida em um domínio muito restrito. Isso acontece, pois é muito complicado para o computador lidar com questões abertas, passíveis de respostas criativas que podem não ter sido previstas na implementação do tutorial.

Já no construcionismo o aluno usa as TIC como máquina para ser ensinada. Isso acontece quando o aprendiz usa as TIC para resolver problemas, usando softwares abertos como no caso das linguagens de programação, processador de texto, e dos sistemas para construção de multimídia ou de páginas da internet. Nesses casos, esses softwares requerem certas ações que são bastante efetivas no processo de construção do conhecimento (VALENTE, 1999).

O aluno tem que descrever para o computador todos os passos do processo de resolução de um problema. O computador executa as ações que foram fornecidas e apresenta na tela um resultado que pode ou não coincidir com o que o aprendiz esperava. Se a resposta coincide, o aluno pode considerar que o problema está resolvido. Se os resultados fornecidos pelo computador não correspondem ao que foi desejado, o aprendiz tem que refletir sobre o que fez e depurar suas idéias, buscando as informações necessárias, incorporando-as à descrição prévia e, com isto, estabelecer o ciclo da descrição-execução-reflexão-depuração-descrição, que se repete até o problema ser considerado resolvido.

No caso de ocorrer um erro e o aluno ter que realizar a depuração de suas idéias, essa tarefa será facilitada pela existência da descrição explícita de como esse problema foi resolvido pela máquina. Essa descrição é a explicitação do raciocínio do aluno, descrito em uma linguagem não ambígua, na qual existe uma correspondência direta entre cada ação fornecida e o comportamento da máquina. Essas características disponíveis no processo de resolução de problema por intermédio do computador facilitam a análise da descri- 
ção fornecida de modo que o aprendiz possa achar seus erros (bugs) e o professor possa entender o que ele está fazendo e pensando. Portanto, o processo de achar e corrigir o erro constitui uma oportunidade única para o aprendiz construir novos conhecimentos. Isso ocorre porque ele tem que buscar novas informações (conceitos ou estratégias), atribuir significado a elas, de modo que possam ser aplicadas na resolução do problema.

Além de fornecer condições para a construção de novos conhecimentos, o uso de softwares abertos permite também trabalhar conceitos sobre aprender a aprender ou sobre como pensar. Isso acontece quando as descrições sobre a resolução de um mesmo problema, que diferentes alunos passam para o computador, são usadas como objetos de estudo e de discussão. Essas descrições podem ser comparadas sob a ótica da eficiência das idéias, estratégias e estilos de resolução de problema utilizados. Nesse caso, o aprendiz começa a pensar sobre seus mecanismos de raciocínio e de pensamento. $\mathrm{O}$ aprender a aprender também pode ser trabalhado, uma vez que o aprendiz, no processo de buscar novas informações, está exercitando suas habilidades de aprender.

Entretanto, o ciclo descrição-execução-reflexão-depuração-descrição não acontece, simplesmente, colocando o aprendiz diante do computador. A interação aluno-computador necessita da intervenção de um profissional - agente de aprendizagem - que tenha conhecimento do significado do processo de aprendizagem baseado na construção de conhecimento. Esse profissional pode ser o professor, porém ele tem que entender as idéias do aprendiz e saber como atuar no processo de construção de conhecimento. Só assim ele poderá intervir apropriadamente na situação, de modo a auxiliar o aluno na construção do seu conhecimento. Além disso, o aprendiz, como um ser social, está inserido em ambiente sociocultural, constituído, mais localmente, por colegas e, mais globalmente, por pais, amigos ou pela comunidade em que vive. Ele pode usar todos estes elementos sociais e culturais como fonte de idéias, de informação, ou de busca de problemas para serem resolvidos por intermédio do computador. A interação do aprendiz com o computador e os diversos elementos que estão presentes na atividade de resolução de problemas são mostrados na figura 3 . 


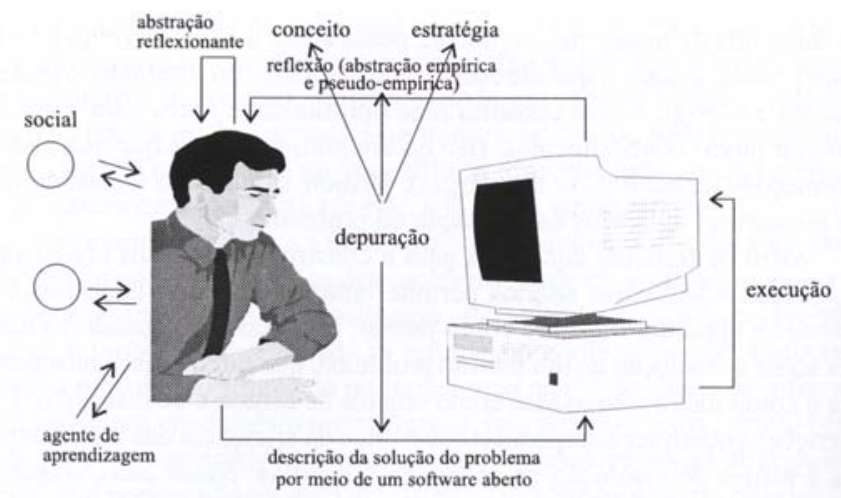

Figura 3 - APRENDIZ UTILIZANDO SOFTWARES ABERTOS PARA A RESOLUÇÃO DE PROBLEMAS OU PROJETOS

\section{A internet (Web) e o instrucionismo}

O uso da internet e, mais especificamente da Web, como fonte de informação, não é muito diferente do que acontece com os tutoriais. Claro que, no caso da Web, existem outras facilidades como a combinação de textos, imagens, animação, sons e vídeos que tornam a instrução muito mais atraente. Porém, a ação que o aprendiz realiza é a de escolher entre opções oferecidas. Ele não está descrevendo o que pensa, mas decidindo entre várias possibilidades oferecidas pela Web. Uma vez escolhida uma opção, o computador apresenta a informação disponível (execução da opção) e o aprendiz pode refletir sobre a mesma - reflexão sobre a opção ou a abstração reflexionante. Com base nestas reflexões o aprendiz pode selecionar outras opções, provocando idas e vindas entre tópicos de informação, ou seja, a ação de navegar na Web, representada na figura 4. 


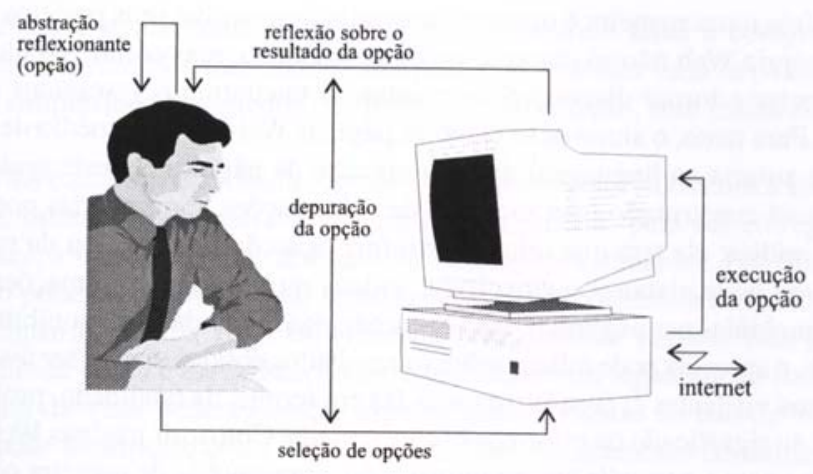

Figura 4 - INTERAÇÃO APRENDIZ-COMPUTADOR NAVEGANDO NA WEB

A Web está ficando cada vez mais interessante e criativa, possibilitando a exploração de um número incrível de assuntos. Porém, se o aprendiz não tem um objetivo nesta navegação, ele pode ficar perdido. A idéia de navegar pode mantê-lo ocupado por um longo período de tempo, porém muito pouco pode ser realizado em termos de compreensão e de transformação dos tópicos visitados em conhecimento. Se esta informação obtida não é posta em uso, não há nenhuma maneira de estarmos seguros de que o aluno compreendeu o que está fazendo. Nesse caso, cabe ao professor suprir essas situações para que a construção do conhecimento ocorra.

\section{A internet (Web) e o construcionismo}

Existem basicamente duas maneiras de como a Web pode ser usada na construção de conhecimento. A primeira, como foi mencionado acima, quando o aluno está resolvendo um problema ou um projeto e necessita de informações. Essas informações podem ser conseguidas via Web. $\mathrm{O}$ aluno pode visitar páginas Web de outros projetos, de instituições que trabalham na área ou mesmo entrar em contato com colegas ou especialistas. A construção de conhecimento ocorre quando o aprendiz ressignifica essas informações no contexto do seu projeto. 
Uma outra maneira é quando o aprendiz desenvolve seus projetos usando a própria Web não só como fonte de informação, mas como veículo para representar e tornar disponível os resultados encontrados (FAGUNDES et al. 1999). Para tanto, o aluno deve elaborar páginas Web por intermédio de sistemas de autoria ou linguagens de programação de páginas e, neste sentido, o aluno está construindo uma sucessão de informações apresentadas por diferentes mídias: ele tem que selecionar informação da literatura ou da própria Web e/ou pode elaborar textos, fotos, vídeos ou programar animações para serem incluídas nas páginas. Uma vez as páginas montadas e disponibilizadas na Web, o aprendiz pode refletir sobre os resultados obtidos ou receber feedback de outros visitantes e, com isto depurá-las em termos da qualidade, profundidade e do significado da informação apresentada. Construir páginas Web cria a chance para o aprendiz buscar informação, apresentá-la de maneira coerente, analisar e criticar essa informação apresentada. Nesse sentido, estabelece-se o ciclo descrição-execução-reflexão-depuração-descrição como mostra a figura a seguir:

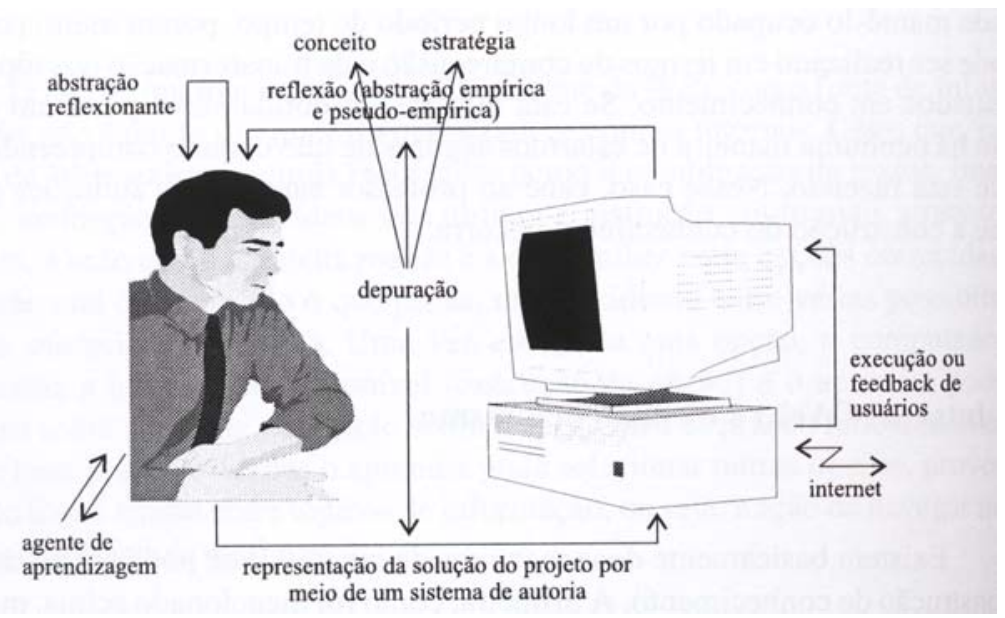

Figura 5 - INTERAÇÃO APRENDIZ-COMPUTADOR USANDO SISTEMA DE AUTORIA PARA ELABORAR PÁGINAS NA WEB

O estabelecimento do ciclo está relacionado com a adequação da representação da informação de forma coerente e de maneira significativa. O conteúdo pode ser rico ou pobre, dependendo de quanto o aprendiz compreende a 
informação apresentada nas suas páginas. Ele pode saber e compreender muito se o assunto foi trabalhado, mas pode compreender nada se os assuntos foram simplesmente copiados das fontes de informação, sem muita elaboração.

Nos casos em que os alunos não estão muito envolvidos com a aprendizagem, estando mais interessados em ter um produto para ser entregue ao professor, a internet acaba facilitando a vida destes estudantes. Por exemplo, o aluno pode facilmente copiar informações para produzir um trabalho escrito ou construir página Web. Esta facilidade de produzir páginas Web por intermédio da cópia e da utilização da informação sem significação tem sido, do ponto de vista educacional, o aspecto mais criticado do uso da Web. O aluno pode facilmente desenvolver um trabalho esteticamente fantástico, aparentemente profundo e sofisticado do ponto de vista de conteúdo, porém sem compreender muito do que foi realizado. MALTEMPI (2000) menciona diversos projetos de pesquisa que abordam essa problemática, exigindo o uso de certas estratégias para o professor se certificar que o produto final foi realmente construído pelo aluno.

Uma outra facilidade que a internet oferece é a possibilidade do aluno encontrar serviços que vendam trabalhos já prontos. BENTON (2001) menciona um estudo realizado com alunos que usam a internet, mostrando que um, entre cinco estudantes entrevistados, conhecia alguém que já tinha se aproveitado deste recurso para copiar artigos ou colar em provas.

Finalmente, uma outra dificuldade com a produção de páginas Web é a questão da depuração das informações ou das idéias construídas. Os sistemas de autoria ou mesmo as linguagens para construção de páginas Web ainda não dispõem de mecanismos para checar a validade de informação utilizada. Além disso, estes sistemas não exigem que o aprendiz descreva tudo o que está pensando, enquanto constrói sua página. Assim, é necessário gerar algumas estratégias para que as páginas Web criadas sejam vistas por outras pessoas, que forneçam feedback para que os alunos percebam as distorções em suas idéias e possam depurá-las. MALTEMPI (2000) trabalhou com estudantes de $5^{\text {a }}$ e e $6^{\text {a }}$. séries do Ensino Fundamental envolvidos na construção de páginas Web sobre temas diversos. Nesse estudo foram avaliadas diversas situações idealizadas para incentivar a depuração das páginas Web criadas e, assim, favorecer a construção de conhecimento por parte dos estudantes. Os resultados obtidos mostraram a importância da participação dos estudantes na escolha do tema do projeto que desenvolvem e da criação de situações nas quais os estudantes apresentam suas idéias e trabalhos, de forma presencial ou não, e recebem feedback. 
Todo o potencial educacional que a Internet oferece tanto pode ser utilizado para o aluno realmente construir novos conhecimentos quanto para obter produtos sofisticados e interessantes, mas que não contribuem para o desenvolvimento do seu conhecimento. Mais uma vez, cabe ao professor saber criar condições para que conceitos e estratégias sejam trabalhados em atividades usando ou não a Internet. Como foi dito, não é a presença da internet que garante a construção de conhecimento, mas o que o aluno faz com a informação que obtém por intermédio da internet.

\section{A internet e a educação a distância}

Existem diferentes maneiras de conceber a Educação a Distância (EAD) e dependendo da abordagem pedagógica utilizada, ela pode ou não contribuir para o processo de construção de conhecimento. A abordagem "broadcast" usa os meios tecnológicos para passar informação aos aprendizes. No outro extremo desse espectro de possibilidades, está o suporte ao processo de construção de conhecimento via internet, que temos denominado de "estar junto virtual" (vALENTE, 2000). Uma abordagem intermediária é a implementação da "escola virtual", que nada mais é do que o uso das tecnologias de telemática para criar a versão virtual da escola tradicional.

A abordagem broadcast é baseada na idéia dos softwares educacionais. O professor do curso organiza a informação de acordo com uma sequiência que ele entende ser a mais adequada e essa informação é enviada ao aluno, utilizando-se dos meios tecnológicos como já aconteceu com o material impresso, o rádio e a televisão ou a internet. No caso de usar a internet, o professor armazena as lições em um determinado arquivo, em um servidor e os alunos, por intermédio de computadores ligados à rede, podem ter acesso a esse servidor, ao arquivo e conseqüentemente às lições.

O importante nessa abordagem é que o professor não interage com o aluno, não recebe nenhum retorno deste e portanto, não tem idéia de como essa informação está sendo compreendida ou assimilada pelo aprendiz.

A virtualização da escola tradicional é uma outra abordagem de EAD que pode ser entendida como a implementação, via telemática, do ambiente tradicional da escola, onde o processo educacional é centrado no professor, que detém a informação e passa-a para o aprendiz. No entanto, como aconte- 
ce na sala de aula tradicional, nessa modalidade de EAD existe alguma interação entre o aluno e o professor, feita via internet: tanto o professor passa informação para o aluno, quanto o aluno envia suas tarefas para o professor. Semelhante ao que foi discutido nos usos da internet no instrucionismo, na virtualização da escola, a interação professor-aluno resume-se em verificar se o aprendiz memorizou a informação fornecida ou requer uma aplicação direta da informação fornecida em um domínio muito restrito.

Mesmo com uma qualidade educacional um pouco melhor do que a abordagem broadcast, a interação aluno-professor pode não ser ainda suficiente para criar condições para o aluno construir conhecimento. Nesse sentido, essa abordagem de EAD tem os mesmos problemas que a situações do ensino nas escolas tradicionais. É por essas razões que a caracterizamos como sendo a virtualização do ensino tradicional e nesse sentido, estamos economizando o fato de essa "escola virtual" não ter paredes e as atividades de ensino acontecerem em um tempo diferente dos costumeiros 50 minutos.

A implantação de uma abordagem de EAD que permite a construção de conhecimento envolve o acompanhamento e assessoramento constante do aprendiz no sentido de poder entender o que ele faz, para ser capaz de propor desafios e auxiliá-lo a atribuir significado ao que está realizando. Só assim ele consegue processar as informações, aplicando-as, transformandoas, buscando novas informações e, assim, construindo novos conhecimentos. Esse acompanhamento consiste no "estar junto" do aluno de modo virtual, via internet.

$\mathrm{Na}$ abordagem de EAD do "estar junto virtual", a interação do professor com o aluno deve ser no sentido de usar a internet para a realização do ciclo descrição-execução-reflexão-depuração-descrição (VALENTE, 1999) via rede. Esse ciclo se inicia com o aluno engajado na resolução de um problema ou projeto. A ação do aluno produz resultados que podem servir como objetos de reflexões. Estas reflexões podem gerar indagações e problemas, e o aluno pode não ter condições para resolvê-los. Nessa situação, ele pode enviar essas questões ou uma breve descrição do que ocorre para o professor. Este professor reflete sobre as questões solicitadas e envia sua opinião, ou material, na forma de textos e exemplos de atividades que poderão auxiliar o aluno a resolver seus problemas. $\mathrm{O}$ aluno recebe essas idéias e tenta colocá-las em ação, gerando novas dúvidas, que poderão ser resolvidas com o suporte do professor. Com isso, estabelece-se um ciclo que mantém o aluno no processo de realização de atividades inovadoras, gerando conhecimento sobre como desenvolver essas ações, porém com o suporte do professor. Assim, a internet pode propiciar o "estar junto" do professor com o aluno, vivenciando com ele 
o processo de construção do conhecimento. A figura 6 ilustra o "estar junto virtual".

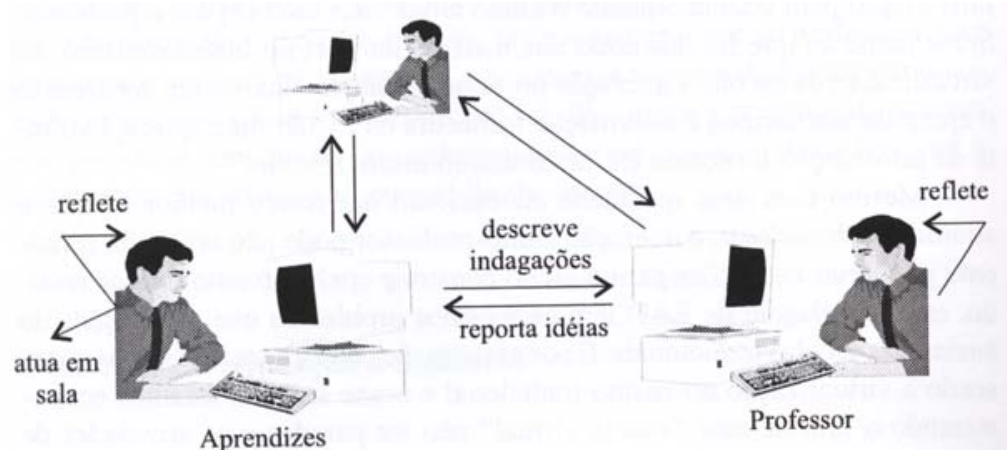

Figura 6 - CICLO QUE SE ESTABELECE NA INTERAÇÃO ALUNO-PROFESSOR, NO "ESTAR JUNTO" VIA INTERNET

Essa abordagem de EAD vai além da realização de cursos a distância, que se restringe a tornar disponível a informação e verificar se essa informação foi retida. Isso não garante que o aluno está construindo novos conhecimentos. Para que isto ocorra, as interações com o aprendiz devem enfatizar a participação do professor nas atividades de planejamento, observação, reflexão e análise do trabalho que o aluno está realizando, ou seja, criar condições para o professor "estar junto", ao lado do aluno, vivenciando e auxiliando-o a resolver seus problemas.

\section{Conclusões}

A análise dos diferentes usos da internet e do computador na educação, permite-nos concluir dois resultados importantes. Primeiro, que a Internet pode tanto servir para passar informação ao aprendiz, quanto auxiliar o processo de construção do conhecimento e de compreensão do que fazemos. Segundo, que a maneira mais adequada de uso de internet ainda depende da intenção pedagógica do professor. 
O uso da internet para auxiliar o aprendiz a obter informação, sem compreender o que está fazendo, é uma mera informatização do atual processo pedagógico. Já a possibilidade que a internet oferece como ferramenta, para ajudar o aprendiz a construir conhecimento e a compreender o que faz, constitui uma verdadeira revolução do processo de aprendizagem e uma chance para transformar a escola.

A análise feita mostrou também que o professor tem um papel fundamental no processo de aprendizagem. Sem o professor preparado para desafiar, desequilibrar o aprendiz, é muito difícil esperar que a internet per se crie as situações para ele aprender. A preparação desse professor é fundamental para que a educação dê o salto de qualidade e deixe de ser baseada na transmissão da informação e na realização de atividades, para ser baseada na construção do conhecimento pelo aluno.

\section{REFERÊNCIAS}

BENTON, J. Students prefer web for academic research, new pew survey shows. The Dallas Morning News: Education Extra. Disponível em: <http://www.dallasnews.com/ cgi-bin/print.c...com/education/461784_internetkids_0.html> Acesso em: 11/09/2001.

FREIRE, P. Pedagogia do oprimido. Rio de Janeiro: Paz e Terra, 1970.

HEIDE, A.; STILBORNE, L. Guia do professor para a internet: completo e fácil. Porto Alegre: Artes Médicas Sul, 2000.

MALTEMPI, M. Construção de páginas web: depuração e especificação de um ambiente de aprendizagem. Campinas, 2000. Tese (Doutorado) - Departamento de Computação e Automação da Faculdade de Engenharia Elétrica e de Computação, Universidade Estadual de Campinas.

PAPERT, S. Constructionism: a new opportunity for elementary science education. Proposta ao national science foundation não publicada. Massachusetts: Massachusetts Institute of Technology, 1986.

PIAGET, J. Fazer e compreender. São Paulo: Melhoramentos, 1978.

REPORT OF THE WEB-BASED EDUCATION COMMISSION. The power of the internet for learning: moving from promise to practice. Washington, DC: Commission to the President and the Congress of the United States, 2000. 
VALENTE, J. A. Educação a distância: uma oportunidade para mudança no ensino. In: MAIA, C. (Org.). ead.br: educação à distância no Brasil na era da internet. São Paulo: Anhembi Morumbi, 2000. p. 97-122.

VALENTE, J. A. Análise dos diferentes tipos de sofware usados na educação. In: (Ed.). Computadores na sociedade do conhecimento. Campinas: Nied - Unicamp, 1999. p. 89-110.

FAGUNDES, L.; SATO, L. S.; MAÇADA, D. L. Aprendizes do futuro: as inovações começaram. MEC/SEED/Proinfo. Disponível em: 〈http://www.proinfo.gov.br〉 Acesso em: 1999. (Coleção: informática para a mudança em educação).

Texto recebido em 10 fev. 2002 Texto aprovado em 22 abr. 2002 